\title{
Retrosternal thyroid mass resulting in axillosubclavian vein thrombosis
}

\author{
Abdullah Mohammad Khan, Sunniya Khan
}

Department of Internal Medicine, Rutgers-NJMS, Newark, New Jersey, USA

\section{Correspondence to} Dr Abdullah Mohammad Khan, khana8@njms.rutgers.edu
CrossMark

To cite: Khan AM, Khan S.
BMJ Case Rep Published
online: [please include Day
Month Year] doi:10.1136/
bcr-2013-202450

\section{DESCRIPTION}

An 89-year-old man with known thyroid goitre presented to the emergency department with right arm swelling for 5 days. There were no dilated head, neck or upper extremity vessels on examination but the right upper extremity was asymmetrically enlarged compared with the left. An elevated D-dimer prompted venous Doppler studies that confirmed acute thrombosis within the right subclavian vein. This was further evaluated with a modified CT angiogram protocol to assess the venous vasculature.

The scout image (figure 1) demonstrated tracheal deviation secondary to a partially calcified mass in the mediastinum, consistent with known diagnosis of goitre. There was an enlarged heterogeneous thyroid gland with areas of calcification, significant mass effect on the surrounding vasculature and a filling defect within the right axillosubclavian vein (figure 2). Numerous collaterals were noted along the right neck hemithorax (figure 3). He was started on anticoagulation that was eventually stopped due to upper gastrointestinal bleed. He refused biopsy and surgery of the thyroid mass.

There are two types of deep vein thrombosis (DVT) of the upper extremities: primary (venous thoracic outlet syndrome, effort-related and idiopathic) and secondary (catheter-associated, cancerassociated, trauma-related and oestrogen-related). ${ }^{1}$ Mediastinal masses fall within the cancer-associated category of secondary DVT. These masses are usually malignant in nature although Santos and Ghalili ${ }^{2}$ reported a case of upper extremity DVT produced by a large retrosternal goitre. The management is anticoagulation with or without thrombolysis, catheter

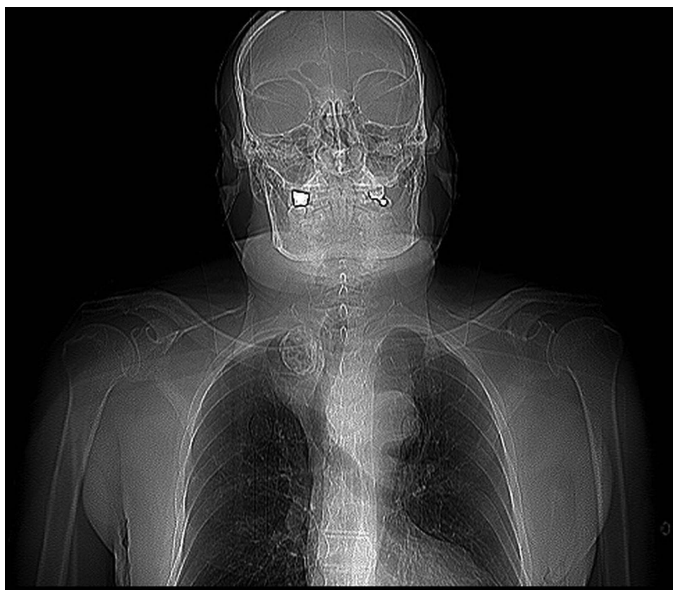

Figure 1 Scout image demonstrating tracheal deviation to the right of midline secondary to a large, partially calcified mass in the mediastinum.

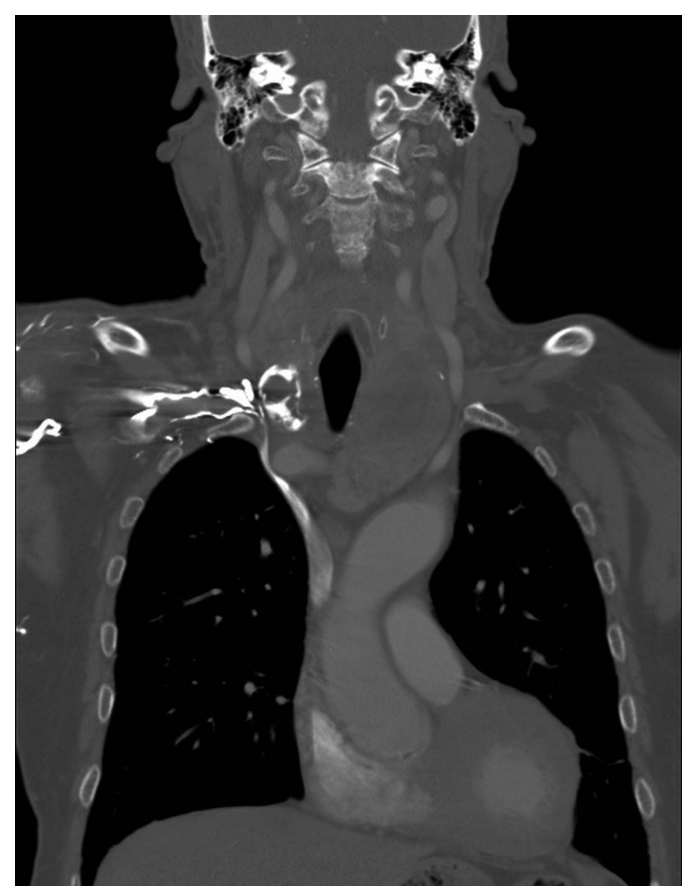

Figure 2 CT angiogram revealing a markedly enlarged, heterogeneous thyroid gland with calcification exerting significant mass effect on the superior aspect of the superior vena cava and right brachiocephalic vein. There is a filling defect within the right subclavian and right axillary veins consistent with thrombosis.

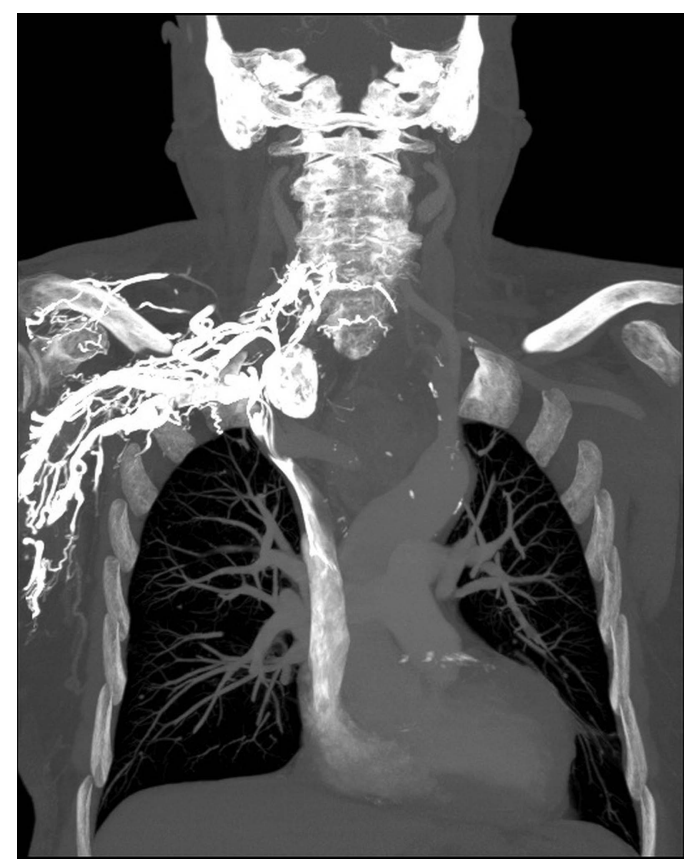

Figure 3 CT angiogram demonstrating numerous collaterals along the right neck hemithorax. 
intervention or surgical intervention depending on the presence or absence of severe symptoms and signs. ${ }^{1}$

\section{Learning points}

- Upper extremity deep venous thrombosis can rarely result from retrosternal thyromegaly.

- The mainstay of treatment is anticoagulation to alleviate symptoms, prevent thrombus progression, pulmonary embolism and post-thrombotic syndrome.

- In the presence of severe symptoms and signs, thrombolysis, catheter intervention or surgical intervention may be indicated.
Contributors AMK contributed to the management of the patient and manuscript preparation. SK contributed to the manuscript preparation. Dr Bernardo Stein was attending on service. AMK is the guarantor.

Competing interests None.

Patient consent Obtained.

Provenance and peer review Not commissioned; externally peer reviewed.

\section{REFERENCES}

1 Kucher N. Clinical practice. Deep-vein thrombosis of the upper extremities. N Eng/ J Med 2011;364:861-9.

2 Santos GH, Ghalili K. Axillosubclavian vein thrombosis produced by retrosternal thyroid. Chest 1990;98:1281-3.

Copyright 2014 BMJ Publishing Group. All rights reserved. For permission to reuse any of this content visit http://group.bmj.com/group/rights-licensing/permissions.

BMJ Case Report Fellows may re-use this article for personal use and teaching without any further permission.

Become a Fellow of BMJ Case Reports today and you can:

- Submit as many cases as you like

- Enjoy fast sympathetic peer review and rapid publication of accepted articles

- Access all the published articles

- Re-use any of the published material for personal use and teaching without further permission

For information on Institutional Fellowships contact consortiasales@bmjgroup.com

Visit casereports.bmj.com for more articles like this and to become a Fellow 